\title{
Pilot-Plant Scale 12 kW Microwave Irradiation Reactor for Woody Biomass Pretreatment
}

\author{
Naoki HASEGAWA $^{\dagger \mathrm{a})}$, Student Member, Tomohiko MITANI ${ }^{\dagger \mathrm{b})}$, Naoki SHINOHARA ${ }^{\dagger c)}$, Members , \\ ${\text { Masakazu DAIDAI }{ }^{\dagger \dagger} \text {, Yoko KATSURA }}^{\dagger \dagger}$, Hisayuki SEGO ${ }^{\dagger \dagger}$, and Takashi WATANABE ${ }^{\dagger d)}$, Nonmembers
}

\begin{abstract}
SUMMARY A simple, low reflection, and highly-efficient pilot-plant scale microwave irradiation reactor for woody biomass pretreatment was fabricated. Pretreatment is an essential process for effective bioethanol production. The fabricated reactor consists of 8 microwave irradiators which are attached to a metal pipe. The woody biomass mixture which contains water and organic acid flows through the metal pipe and is heated by microwaves at a total power of $12 \mathrm{~kW}$. To design the microwave irradiators, we used a 3D Finite Element Method (FEM) simulator, which was based on the measured complex permittivity data of the woody biomass mixture. The simulation results showed that the reflection coefficient $\left|S_{11}\right|$ from the reactor was less than $-30 \mathrm{~dB}$ when the woody biomass mixture temperature was between $30^{\circ} \mathrm{C}$ and $90^{\circ} \mathrm{C}$. Finally, we experimentally confirmed that the fabricated irradiation reactor yielded a microwave absorption efficiency of $79 \%$.

key words: Microwave heating, permittivity measurement, finite element method, magnetron
\end{abstract}

\section{Introduction}

Bioethanol derived from woody biomass is expected to serve as an alternative to fossil fuels, because it is renewable, sustainable, and carbon-neutral. Woody biomass consists of cellulose (40-50\%), hemicellulose (10-20\%), and lignin $(20-40 \%)$. Bioethanol production from woody biomass requires an extra pretreatment process before saccharification and fermentation of the cellulose and hemicellulose, because the lignin coating on the cellulose and hemicellulose prevents enzyme access to the saccharification process. In the pretreatment process, the molecular binding of the lignin is broken and the coating is removed from the cellulose and hemicellulose. An effective pretreatment process is therefore essential for efficient bioethanol production from woody biomass. A lot of pretreatment methods were researched and proposed [1]-[4].

Since the 1980s, microwave pretreatment for enzymatic saccharification and fermentation has been extensively investigated due to its potential application to woody

\footnotetext{
Manuscript received March 11, 2014.

Manuscript revised June 20, 2014.

${ }^{\dagger}$ The authors are with Research Institute for Sustainable Humanosphere(RISH), Kyoto University, Uji, Kyoto 611-0011, Japan.

${ }^{\dagger \dagger}$ The authors are with Japan Chemical Engineering \& Machinery Co., Ltd. , 7-1 Oike, Konan, Shiga 520-3213, Japan.

a) E-mail: naoki_hasegawa@ @ish.kyoto-u.ac.jp

b) E-mail: mitani.tomohiko.3u@kyoto-u.ac.jp

c) E-mail: shino@ rish.kyoto-u.ac.jp

d) E-mail: twatanab@rish.kyoto-u.ac.jp

DOI: 10.1587/transele.E97.C.986
}

biomass reactors. H. Ooshima et al. and J. Azuma et al. reported that microwave heating with optimized heat conditions in aqueous media could accelerate the enzymatic saccharification of woody biomass [5]-[11]. The microwave process has been extended to various aqueous and organosolv pretreatment reactors with acidic, alkaline and oxidative catalysts. Microwave pretreatment enables faster heating than conventional methods, and the process is applicable to a wide variety of woody biomass including hardwood and recalcitrant softwood.

In conventional studies, pretreatment reactors with microwave irradiation was presented [12]-[14]. However, the proposed reactors in the conventional studies were the small capacity experiment system for laboratory. Therefore, it is necessary for future industrialization of bioethanol production from woody biomass to increase in size of pretreatment reactor.

In this paper, the $50 \mathrm{~L}$ class pretreatment reactor with $12 \mathrm{~kW}$ microwave irradiation was designed and fabricated. For the industrial production of bioethanol, the cost of the processing facilities should be minimized. Therefore, we developed a low cost pilot-plant scale microwave reactor which enables highly-efficient energy transfer from commercially available magnetrons to the reactor without the use of a matching tuner, isolator, or power monitor. In addition, the calculation method of microwave absorbing efficiency was shown in this paper. This method make it possible to evaluate the absorbing efficiency without use of RF observation devices at running the reactor.

\section{Microwave Pretreatment Reactor}

The development of the pilot-plant scale $12 \mathrm{~kW}$ microwave irradiation reactor as shown in Fig. 1 was designed. This reactor has 8 microwave irradiators which consist of $2.45 \mathrm{GHz}$ magnetrons (output power: $1.5 \mathrm{~kW}$ ), waveguides, and glass windows. The total input power is $12 \mathrm{~kW}$. The mixture is irradiated with microwave irradiators attached around the metal pipe.

We selected the 250A pipe-size, which is defined by the Japanese Industrial Standards (JIS), for the pretreatment volume $50 \mathrm{~L}$. The outer and inner diameters of the $250 \mathrm{~A}$ pipe-size are $267.4 \mathrm{~mm}$ and $254.2 \mathrm{~mm}$, respectively. The irradiators were installed not to interfere with each other physically. Eventually, the 4 irradiators were aligned every $90^{\circ} \mathrm{C}$ in the same plane, then another 4 irradiators were 


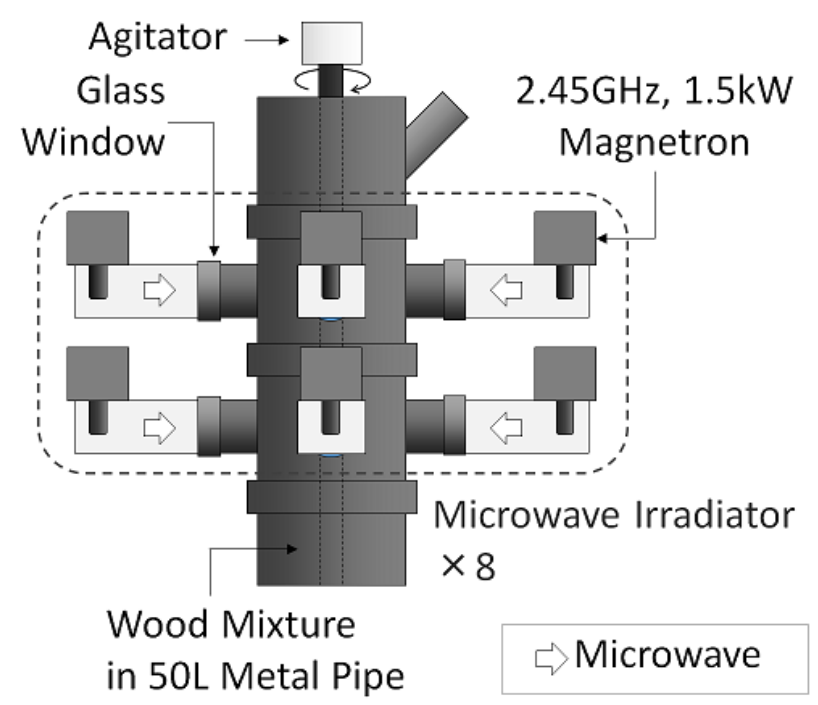

(a)

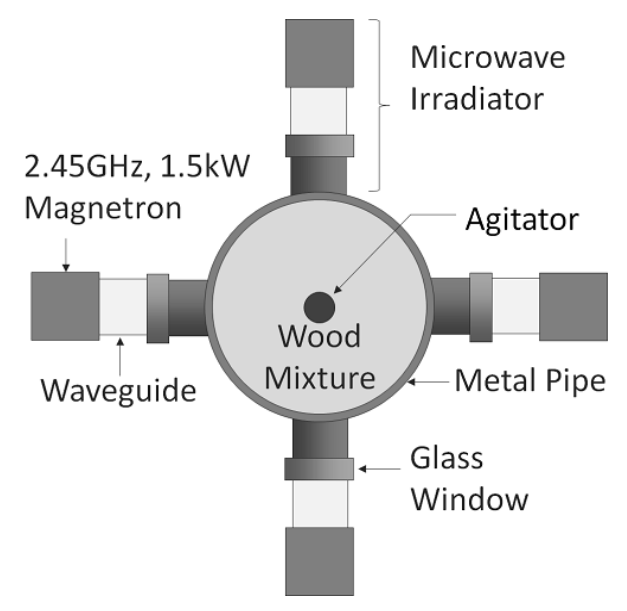

(b)

Fig. 1 Schematics of the pilot-plant scale microwave pretreatment reactor. The developed reactor consists of $2.45 \mathrm{GHz}$ magnetrons, waveguides, glass windows, and a metal pipe. The total input power is $12 \mathrm{~kW}$. (a) side view of the reactor, (b) top view of the reactor.

aligned in a two-tiered manner.

In the reactor design, we first measured the permittivity of the woody biomass mixture. Second, the microwave irradiator was designed by use of a 3D Finite Element Method (FEM) simulator (Murata Software, Femtet) and the obtained permittivity data. Thirdly, we fabricated the reactor incorporating $1.5 \mathrm{~kW}$ magnetrons and multi-port microwave irradiators. Finally, we estimated the absorption efficiency of the reactor from the measured temperature data.

\section{Measurement of Woody Biomass Permittivity}

The permittivity of some liquids including water is dependent on temperature [14]. This temperature dependence af-

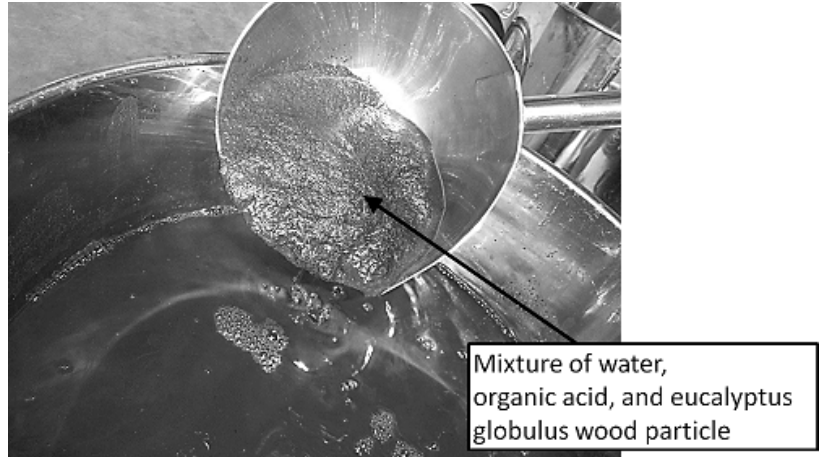

Fig. 2 Mixture of water, organic acid, and eucaryputus globulus wood particles. The mixing ratio was $85 \mathrm{w} / \mathrm{w} \%, 0.03 \mathrm{w} / \mathrm{w} \%$, and $15 \mathrm{w} / \mathrm{w} \%$, respectively.

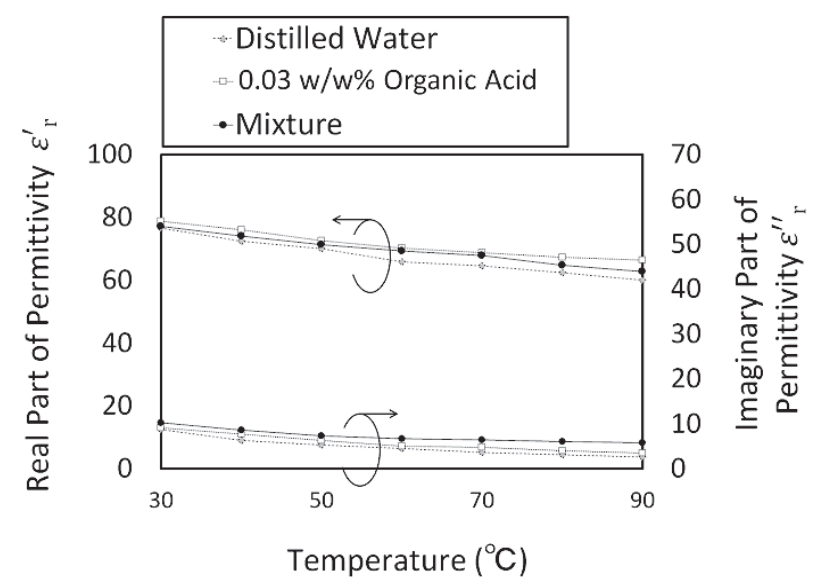

Fig. 3 Temperature dependence of complex relative permittivity at 2.45 $\mathrm{GHz}$. In the mixture, the real part of the permittivity gradually decreased with increasing temperature.

fects the characteristic impedance. Hence, the design of the microwave reactor is greatly influenced by the temperature dependence of the permittivity. Therefore, we measured the permittivity of the woody biomass mixture at $2.45 \mathrm{GHz}$. In this paper, we defined the percent by weight as $\mathrm{w} / \mathrm{w} \%$. The mixture shown in Fig. 2 consists of $85 \mathrm{w} / \mathrm{w} \%$ water, $0.03 \mathrm{w} / \mathrm{w} \%$ organic acid, and $15 \mathrm{w} / \mathrm{w} \%$ eucalyptus globulus wood particles. The organic acid is a catalyst which accelerates the exposure of lignin coated cellulose and hemicellulose. We measured the permittivity with a dielectric probe kit (Agilent 8507E) and network analyzer (Agilent $\mathrm{N} 5242 \mathrm{~A}$ ). In this measurement, the mixture was heated and agitated by a hot plate stirrer (AS ONE DP-1S).

The temperature dependence of the complex relative permittivity of mixture of eucalyptus wood particles in 0.03 w/w\% aqueous organic acid was shown in Fig. 3. The data were averaged over ten measurement. The standard variations were less than 1.5 at each temperature. According to Fig. 3, the real part of the relative permittivity was 77.0 and the imaginary part was 10.3 for the mixture at $30^{\circ} \mathrm{C}$. When the temperature of the mixture increased to $90^{\circ} \mathrm{C}$, the real and imaginary parts of the permittivity decreased to 62.6 and 5.80, respectively. The specific values at each 
Table 1 Simulation and calculation results for the temperature dependence of various properties

\begin{tabular}{|c|c|c|c|c|c|}
\hline \multirow{2}{*}{$\begin{array}{c}\text { Temperature } \\
\left({ }^{\circ} \mathrm{C}\right)\end{array}$} & \multicolumn{2}{|c|}{ Permittivity } & \multirow{2}{*}{$\begin{array}{l}\left|S_{11}\right| \\
(\mathrm{dB})\end{array}$} & \multirow{2}{*}{$\begin{array}{c}\text { Absorption } \\
\text { Efficiency (\%) }\end{array}$} & \multirow{2}{*}{$\begin{array}{c}\left|Z_{\text {in }}\right| \\
(\mathrm{Ohm})\end{array}$} \\
\hline & $\epsilon_{\mathrm{r}}^{\prime}$ & $\epsilon_{\mathrm{r}}^{\prime \prime}$ & & & \\
\hline 30 & 77.0 & 10.3 & -36.0 & 94.7 & 27.5 \\
\hline 40 & 74.0 & 8.60 & -31.0 & 93.3 & 27.2 \\
\hline 50 & 71.2 & 7.34 & -32.0 & 94.1 & 27.1 \\
\hline 60 & 69.3 & 6.69 & -32.5 & 94.4 & 27.0 \\
\hline 70 & 67.7 & 6.34 & -34.0 & 94.3 & 26.8 \\
\hline 80 & 64.8 & 5.99 & -35.0 & 94.3 & 26.5 \\
\hline 90 & 62.6 & 5.80 & -35.6 & 94.5 & 26.0 \\
\hline
\end{tabular}

temperature are shown in Table 1. The values for the permittivity of water were the same as those in [15].

The permittivity measurements were conducted in the liquid phase under air pressure condition. Although the mixture temperature is predicted to become above $100^{\circ} \mathrm{C}$ in the actual microwave irradiation experiments, the mixture is not vaporized and the pressure in the metal pipe is increased instead in our irradiation system. Then we need to treat the mixture as liquid (not gas) and therefore we adopted the permittivity of the mixture from $30^{\circ} \mathrm{C}$ to $90^{\circ} \mathrm{C}$, in the liquid phase for numerical simulations.

\section{Design of Irradiator through Numerical Simulations}

We designed a microwave irradiator with a 3D FEM simulator. The simulation model shown in Fig. 4 consists of the magnetron antenna with wave port, waveguide, glass window, and metal pipe. We assumed the metal pipe was filled up with the mixture whose permittivity was obtained from the measurements shown in Fig. 3.

In our simulation, we approximately treated the mixture as homogeneous matter. Although it has inhomogeneity as shown in Fig. 2, the mixture is sufficiently stirred in the metal pipe during microwave irradiation. We therefore introduced the average permittivity of the mixture for numerical simulations.

The absorbing boundary condition was set on the top and bottom surfaces of the metal pipe. The irradiator consisted of a magnetron antenna and a square waveguide, which was attached to the cylindrical glass window of the metal pipe. The $80 \mathrm{~mm}$ diameter and $15 \mathrm{~mm}$ thickness grass was used for the metal pipe window. The size of grass was determined by withstanding pressure of metal pipe.

The magnetron model used for the irradiator was a HITACHI 2M256 whose inner conductor was covered with an alumina dome. The input microwave frequency and power were $2.45 \mathrm{GHz}$ and $1.5 \mathrm{~kW}$, respectively. In the waveguide, it is desirable that only the dominant mode $\mathrm{TE}_{10}$ propagates, because microwave reflection and loss results from higher modes. The cutoff frequency was calculated from the width of square waveguide $W$. When we decided $W=70 \mathrm{~mm}$, the cutoff frequencies of primal mode $\mathrm{TE}_{10}$ and higher mode $\mathrm{TM}_{11}$ were calculated as $2.1 \mathrm{GHz}$ and $2.5 \mathrm{GHz}$, respectively.

We first discuss a 1 port simulation. In this simulation,

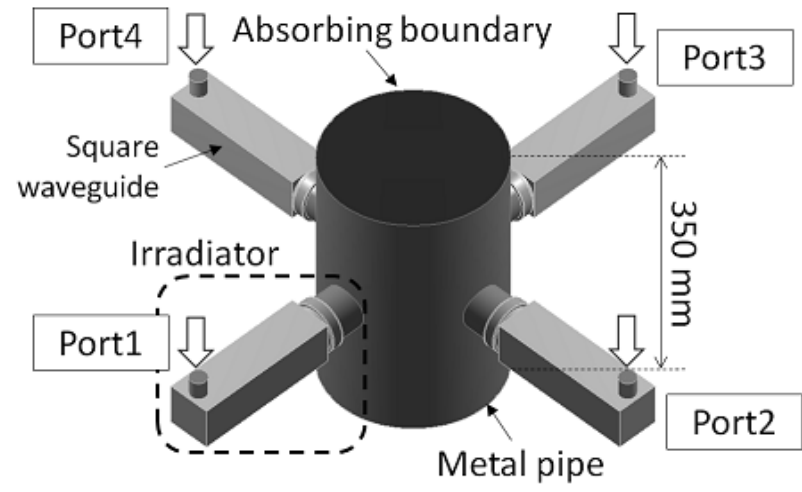

(a)

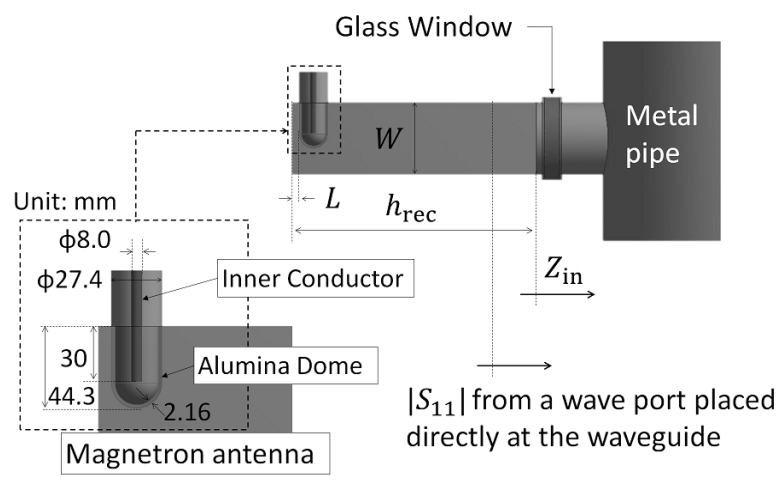

(b)

Fig. 4 Simulation model of the designed microwave irradiator which consists of a magnetron antenna, a square waveguide, and a glass window. (a) 4 port simulation mode (b) detail of irradiator.

$1.5 \mathrm{~kW}$ power was input from a wave port on the coaxial line of magnetron antenna. The size of magnetron antenna and coaxial line was shown in red Fig. 4(b). Using this simulation model, we determined the size of the irradiator that minimizes the reflection coefficient $\left|S_{11}\right|$. The simulation results with varying square waveguide length, $h_{\text {rec }}$, obtained for different values of the insertion position of the magnetron antenna, $L$, were shown in Fig. 5. As shown by the graph, when $h_{\text {rec }}=240 \mathrm{~mm}$ and $L=7 \mathrm{~mm},\left|S_{11}\right|$ reached its lowest value of $-37 \mathrm{~dB}$. A similarly low value of $-31 \mathrm{~dB}$ was also obtained when $h_{\mathrm{rec}}=110 \mathrm{~mm}$ and $L=5.5 \mathrm{~mm}$. The optimum wavelength for this square waveguide is $253 \mathrm{~mm}$ at $2.45 \mathrm{GHz}$. Hence, $\left|S_{11}\right|$ was low when $h_{\text {rec }}$ became this or half of this wavelength.

The frequency characteristics of $\left|S_{11}\right|$ when $h_{\mathrm{rec}}=$ $110 \mathrm{~mm}$ and $L=5.5 \mathrm{~mm}$, and $h_{\mathrm{rec}}=240 \mathrm{~mm}$ and $L=7 \mathrm{~mm}$ were shown in Fig. 6. In addition, the $\left|S_{11}\right|$ from a wave port placed directly at the waveguide was shown in Fig. 6. According to Fig. 6, microwave reflection of the irradiator was reduced by tuning $L$ and $h_{\text {rec }}$ of square waveguide.

Figure 7 shows the temperature dependence of $\left|S_{11}\right|$ and the power absorption when $h_{\mathrm{rec}}=240 \mathrm{~mm}$ and $L=$ $7 \mathrm{~mm}$ at $2.45 \mathrm{GHz}$. $\left|S_{11}\right|$ was less than $-30 \mathrm{~dB}$ and the power 


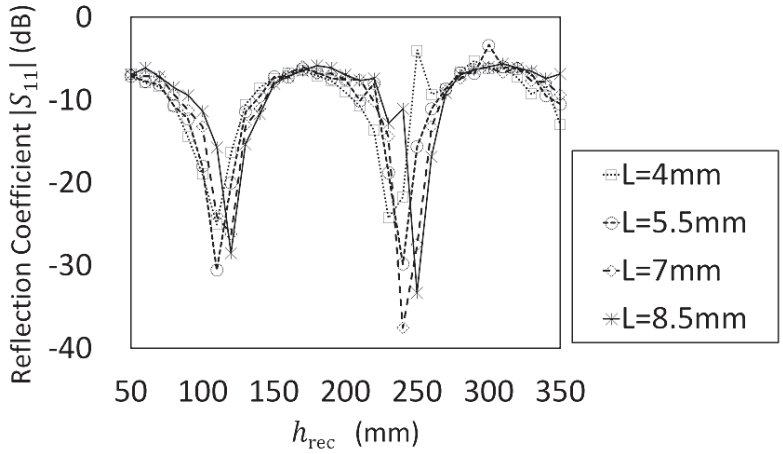

Fig. 5 Simulation results of the microwave reflection coefficient $\left|S_{11}\right|$ with the parameters $h_{\mathrm{rec}}$ and $L .\left|S_{11}\right|$ is lowest when $h_{\mathrm{rec}}=240 \mathrm{~mm}$ and $L=7 \mathrm{~mm}$.

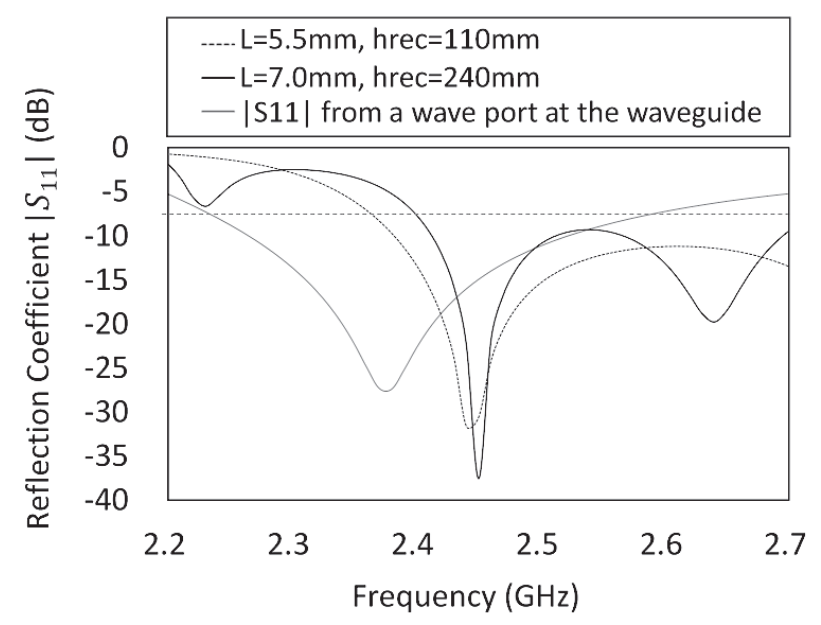

Fig. 6 Frequency characteristics of microwave refraction coefficient $\left|S_{11}\right|$ when $h_{\mathrm{rec}}=110 \mathrm{~mm}$ and $L=5.5 \mathrm{~mm}$, and $h_{\mathrm{rec}}=240 \mathrm{~mm}$ and $L=7 \mathrm{~mm}$. For both sizes, $\left|S_{11}\right|$ is less than $-10 \mathrm{~dB}$ around $2.45 \mathrm{GHz}$.

absorption was more than $1.4 \mathrm{~kW}$. In this simulation model, the input microwave power was $1.5 \mathrm{~kW}$, meaning the absorption efficiency was more than $93 \%$ between $30^{\circ} \mathrm{C}$ and $90^{\circ} \mathrm{C}$. The permittivity of the mixture changed with increasing temperature as shown in Fig. 3, whereas $\left|S_{11}\right|$ and the power absorption hardly changed. The reason for this is that the characteristic impedance in the waveguide is much higher than the input impedance from the waveguide to the metal pipe. The input impedance $\left|Z_{\text {in }}\right|$ calculated by Femtet was $27.5 \Omega$ at $30^{\circ} \mathrm{C}$ and decreased to $26.0 \Omega$ at $90^{\circ} \mathrm{C}$. On the other hand, the characteristic impedance in the waveguide was calculated to be $777 \Omega$ at $2.45 \mathrm{GHz}$ in the $\mathrm{TE}_{10}$ mode, which is sufficiently larger than $\left|Z_{\text {in }}\right|$. Therefore, the permittivity change in temperature hardly affects $\left|S_{11}\right|$ or the power absorption.

Next, we investigated the power absorption distribution in the metal pipe. In this simulation, the microwave was irradiated from 4 wave ports as shown in Fig. 4(a). The total input power was $6.0 \mathrm{~kW}$. The simulation result for the power absorption at a cross-section of the model was shown in Fig. 8. According to Fig. 8, the power absorption in the metal pipe was confirmed. The $5.69 \mathrm{~kW}$ power was ab-

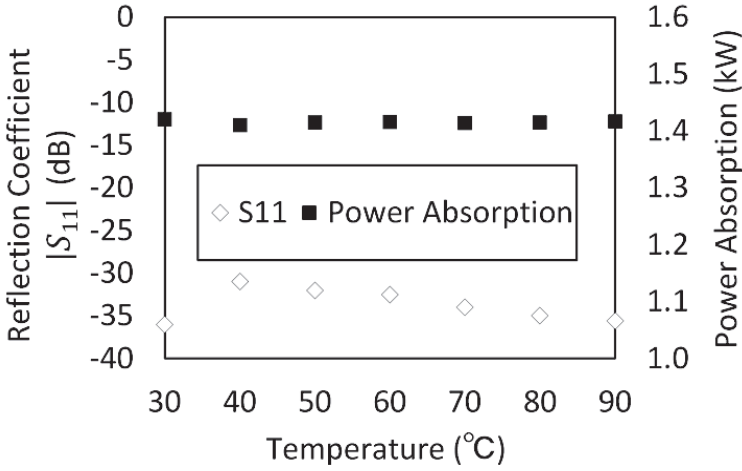

Fig. 7 Temperature dependence of $\left|S_{11}\right|$ and power absorption. $\left|S_{11}\right|$ was less than $-30 \mathrm{~dB}$ and the power absorption was more than $1.4 \mathrm{~kW}$.

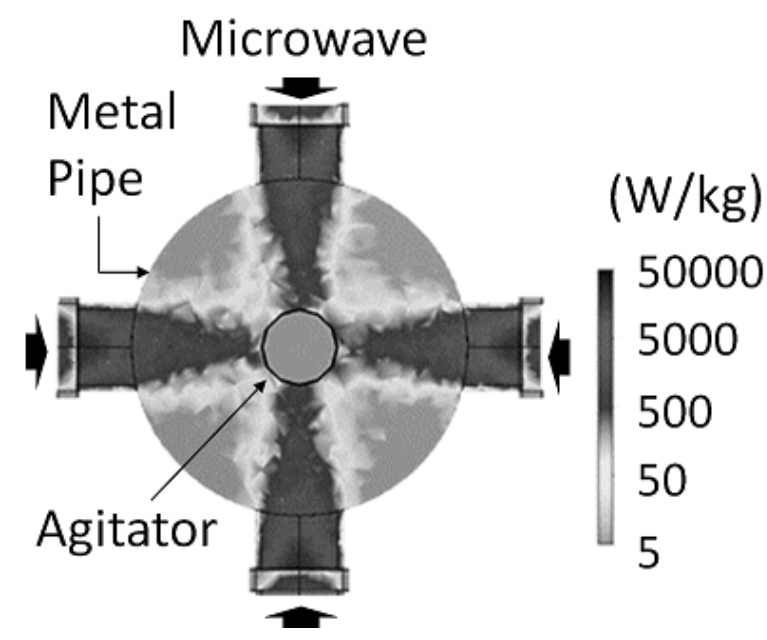

Fig. 8 Power absorption distribution in the metal pipe at $80^{\circ} \mathrm{C}$ mixture temperature.

sorbed in the $80^{\circ} \mathrm{C}$ mixture. The absorption power reduced at nearer center of the metal pipe. Therefore, it is necessary for even heating to agitate. The center pole shown in Fig. 8 was assumed as agitator. We confirmed the center pole has no effect on RF characteristics in the simulation.

Table 1 shows the simulation and calculation results for the temperature dependence of various properties. It can be seen that the input impedance $\left|Z_{\text {in }}\right|$ was affected by the temperature dependence of the permittivity. However, the reflection coefficient $\left|S_{11}\right|$ and the absorption efficiency hardly changed because the microwave power absorbed by the mixture was almost constant, regardless of the temperature.

Lastly, we discuss the isolation between irradiators. We define the port 2 and port 4 as the adjacent ports to the port 1 , and the port 3 as the opposite port to the port 1 , as shown in Fig. 4(a). The simulation results of $\left|S_{21}\right|\left(=\left|S_{41}\right|\right)$ and $\left|S_{31}\right|$ are shown in Fig. 9. According to Fig. 9, both $\left|S_{21}\right|$ and $\left|S_{31}\right|$ were less than $-110 \mathrm{~dB}$. Therefore the microwave irradiation port is sufficiently isolated from the other ports.

\section{Experiment and Discussion}

We fabricated the pilot-plant microwave reactor according 


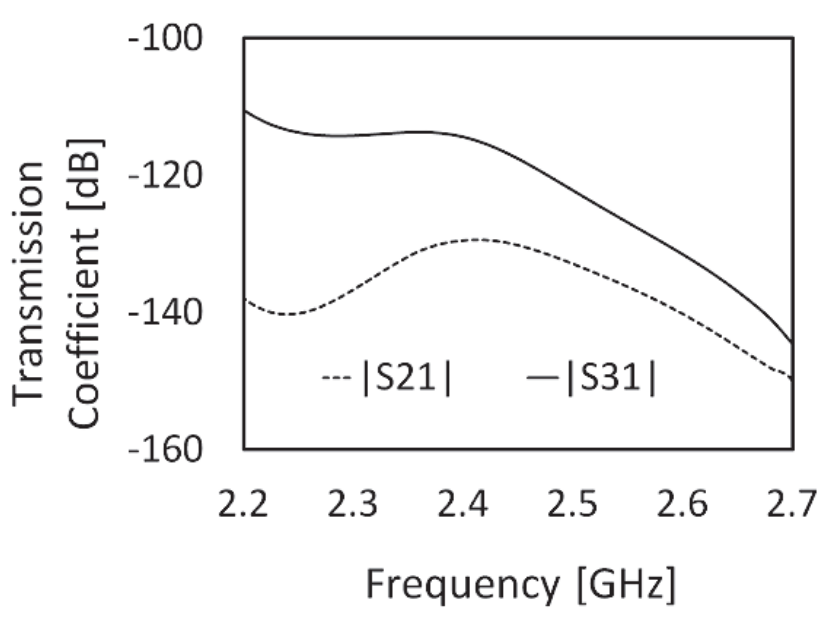

Fig. 9 Transmission coefficient $\left|S_{21}\right|\left(=\left|S_{41}\right|\right)$ and $\left|S_{31}\right|$. Each irradiators was isolated.

to the design presented above. A photograph of the fabricated reactor was shown in Fig. 10. The overall reactor and the microwave irradiator section was shown in Fig. 10(a) and Fig. 10(b), respectively. The reactor consists of $8 \mathrm{mi}-$ crowave irradiators. The volume of the metal pipe is $50 \mathrm{~L}$. A stirring machine is installed to ensure a uniform temperature distribution in the metal pipe. The pretreatments using the aqueous solvent system require a high temperature, which exceeds the boiling point of water under ordinary pressure. Therefore, the microwave reactor was designed to accommodate pressurized reactions up to a maximum of $2.0 \mathrm{MPa}$ at $215^{\circ} \mathrm{C}$ in the sealed metal pipe with glass windows.

The pilot-plant scale microwave irradiation reactor has 8 magnetrons. In general, magnetron has a broad frequency spectrum [16], [17]. We measured the magnetron spectrum with a spectrum analyzer. The measurement results are shown in Table 2. According to the Table 2, the averages of the peak frequency and $-3 \mathrm{~dB}$ bandwidth of the spectrum were $2.4623 \mathrm{GHz}$ and $1.8 \mathrm{MHz}$, respectively. In the simulation results shown in Fig. 6, $\left|S_{11}\right|$ was less than $-20 \mathrm{~dB}$ within the frequency range of magnetron spectrum.

Figure 11 shows the measurement results of the temperature dependence and heat loss, which includes radiation and convection losses. The temperature of the mixture was measured at four points near the irradiator using a fiber-optic thermometer shown in Fig. 10(b). The radiation loss $Q_{\mathrm{r}}$ and convection loss $Q_{\mathrm{c}}$ were calculated with the following equations

$$
\begin{aligned}
& Q_{\mathrm{r}}=e \sigma S\left(T_{\mathrm{st}}^{4}-T_{\mathrm{rt}}^{4}\right), \\
& Q_{\mathrm{c}}=h S\left(T_{\mathrm{st}}-T_{\mathrm{rt}}\right),
\end{aligned}
$$

where $e$ is the emissivity, $\sigma$ is the Stefan-Boltzmann constant, $S$ is the total outer surface area, $T_{\mathrm{st}}$ is the surface temperature of the metal pipe, $T_{\mathrm{rt}}$ is the room temperature, and $h$ is the convective heat transfer coefficient. In this calculation, we assumed that $e=0.35, \sigma=5.66 \times 10^{-8} \mathrm{~W} /\left(\mathrm{m}^{2} \cdot \mathrm{K}^{4}\right), S=$ $0.75 \mathrm{~m}^{2} T_{\mathrm{rt}}=21.4^{\circ} \mathrm{C}(=294.6 \mathrm{~K})$, and $h=14 \mathrm{~W} /\left(\mathrm{m}^{2} \cdot \mathrm{K}\right)$. In addition, $T_{\mathrm{st}}$ was calculated in Appendix and we assumed $\kappa=16.7 \mathrm{~W} /(\mathrm{m} \cdot \mathrm{K})$. Table 3 shows the calculation results of

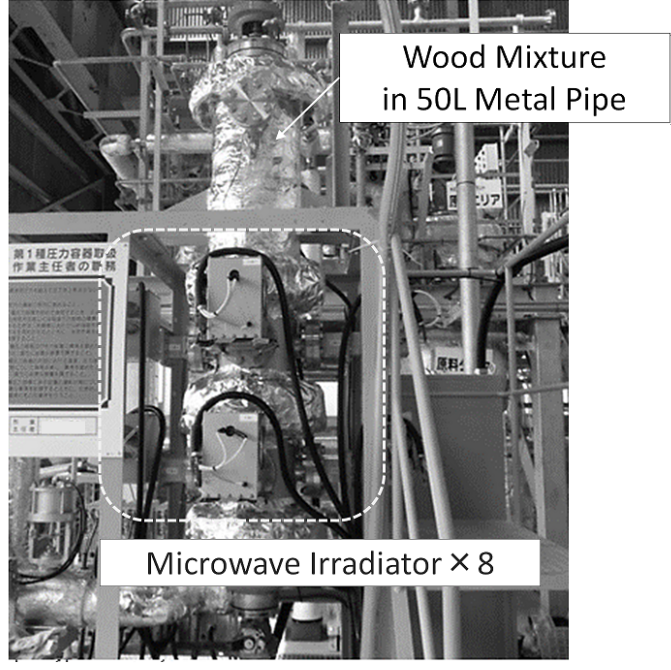

(a)

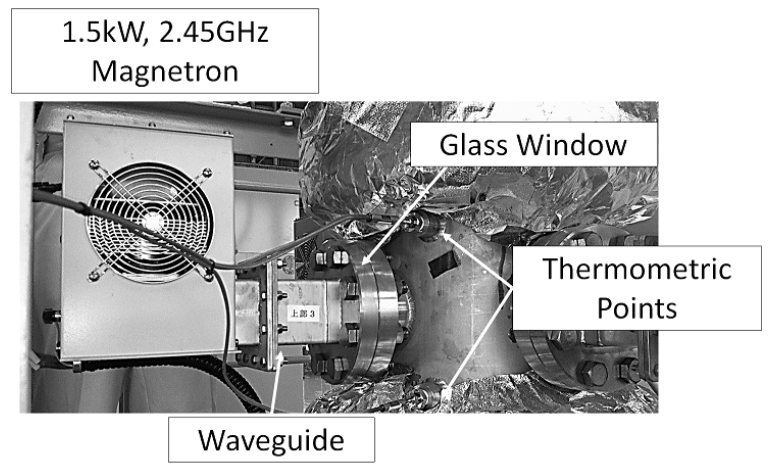

(b)

Fig. 10 Photographs of the fabricated pilot-plant scale microwave irradiation reactor. (a) entire reactor, (b) microwave irradiator section.

Table 2 Measured magnetrons peak frequency and $-3 \mathrm{~dB}$ bandwidth.

\begin{tabular}{lcc}
\hline & Peak Frequency $(\mathrm{GHz})$ & $-3 \mathrm{~dB}$ Bandwidth $(\mathrm{MHz})$ \\
\hline Magnetron 1 & 2.4628 & 1.6 \\
Magnetron 2 & 2.4618 & 1.4 \\
Magnetron 3 & 2.4610 & 1.4 \\
Magnetron 4 & 2.4618 & 1.6 \\
Magnetron 5 & 2.4626 & 3.4 \\
Magnetron 6 & 2.4632 & 1.2 \\
Magnetron 7 & 2.4612 & 2.2 \\
Magnetron 8 & 2.4640 & 1.8 \\
\hline Average & 2.4623 & 1.8 \\
\hline
\end{tabular}

the surface temperature and heat loss. According to Table 3, the differences between the average temperature of mixture $T$ and $T_{\text {st }}$ for the first $10 \mathrm{~min}$ were less than $1{ }^{\circ} \mathrm{C}$. Also, the heat loss $Q\left(=Q_{\mathrm{r}}+Q_{\mathrm{c}}\right)$ was less than $0.40 \mathrm{~kW}$, meaning the ratio of the heat loss to the total magnetron power of $12 \mathrm{~kW}$ was less than $3.3 \%$. In addition, we calculated the $10.5 \%$ and $26.2 \%$ power was lost by heat loss at $100^{\circ} \mathrm{C}$ and $200^{\circ} \mathrm{C}$ mixture temperature. According to this result, it is neces- 
Table 3 Calculation results of the surface temperature and the heat loss.

\begin{tabular}{ccccccc}
\hline $\begin{array}{c}\text { Time } \\
(\mathrm{min})\end{array}$ & $\begin{array}{c}T \\
\left({ }^{\circ} \mathrm{C}\right)\end{array}$ & $\begin{array}{c}T_{\mathrm{st}} \\
\left({ }^{\circ} \mathrm{C}\right)\end{array}$ & $\begin{array}{c}Q_{\mathrm{r}} \\
(\mathrm{kW})\end{array}$ & $\begin{array}{c}Q_{\mathrm{c}} \\
(\mathrm{kW})\end{array}$ & $\begin{array}{c}Q \\
(\mathrm{~kW})\end{array}$ & $\begin{array}{c}Q \\
(\%)\end{array}$ \\
\hline 0 & 21.4 & 21.4 & 0.00 & 0.00 & 0.00 & 0.0 \\
1 & 23.4 & 23.4 & 0.00 & 0.02 & 0.02 & 0.2 \\
2 & 27.6 & 27.5 & 0.01 & 0.06 & 0.07 & 0.6 \\
3 & 31.5 & 31.3 & 0.02 & 0.10 & 0.12 & 1.0 \\
4 & 34.6 & 34.3 & 0.03 & 0.14 & 0.17 & 1.4 \\
5 & 37.5 & 37.2 & 0.03 & 0.17 & 0.20 & 1.7 \\
6 & 41.7 & 41.3 & 0.04 & 0.21 & 0.25 & 2.1 \\
7 & 45.6 & 45.1 & 0.05 & 0.25 & 0.30 & 2.5 \\
8 & 48.6 & 48.1 & 0.06 & 0.28 & 0.34 & 2.8 \\
9 & 51.0 & 50.4 & 0.07 & 0.30 & 0.37 & 3.1 \\
10 & 53.1 & 52.4 & 0.07 & 0.33 & 0.40 & 3.3 \\
- & 100 & 98.3 & 0.22 & 1.04 & 1.26 & 10.5 \\
- & 200 & 196 & 0.78 & 2.36 & 3.14 & 26.2 \\
\hline
\end{tabular}

sary for effective running of the reactor to reduce the heat loss by use of an insulating material.

We calculated the microwave absorption efficiency using the temperature dependence of the mixture. The power absorption $P_{\mathrm{a}}$ can be expressed by the following differential equation

$$
P_{\mathrm{a}}=m C_{\mathrm{p}} \frac{\mathrm{d} T}{\mathrm{~d} t},
$$

where $m$ is the total mass and $C_{\mathrm{p}}$ is the specific heat. We consider the heat loss from the metal pipe to be negligible because it was so low for the first $10 \mathrm{~min}$. Also, we assume $m$ and $C_{\mathrm{p}}$ are constant. Thus, the temperature as a function of time can be written as the following linear equation

$$
T(t)=\frac{\mathrm{d} T}{\mathrm{~d} t} t+T_{0}=\frac{P_{\mathrm{a}}}{m C_{\mathrm{p}}} t+T_{0},
$$

where $T_{0}$ is the initial temperature. We fitted (4) to the measurement data with the least-squares method to estimate the power absorption. The fitted liner function is shown by the dashed line in Fig. 11. The gradient of the linear function $\mathrm{d} T / \mathrm{d} t$ was $0.056 \mathrm{~K} / \mathrm{s}$. The specific heat of the mixture $C_{\mathrm{p}}$, which was measured with a calorimeter, was $3.60 \mathrm{~J} /(\mathrm{g} \cdot \mathrm{K})$ and the mass $m$ was $49 \mathrm{~kg}$. Therefore, the power absorption $P_{\mathrm{a}}$ was $9.5 \mathrm{~kW}$ from Eq. (3) and the absorption efficiency was $79 \%$ with a total magnetron power of $12 \mathrm{~kW}$.

The absorption efficiency was declined by 14 points compared with simulation results. This energy loss is caused by thermal dissipation from the reactor. In the above calculation, we do not take thermal losses into account. However, the heat transfer through the metal pipe provides thermal radiation loss and convection loss. Hence these losses make apparent absorption efficiency lessen even though the woody biomass mixture absorbs the microwave efficiently.

In this experiment, we confirmed the temperature increase to more than $200^{\circ} \mathrm{C}$ and succeed to provide acceleration of the enzymatic saccharification.

\section{Conclusion}

We designed a simple, low reflection, and highly-efficient microwave reactor for woody biomass pretreatment. First,

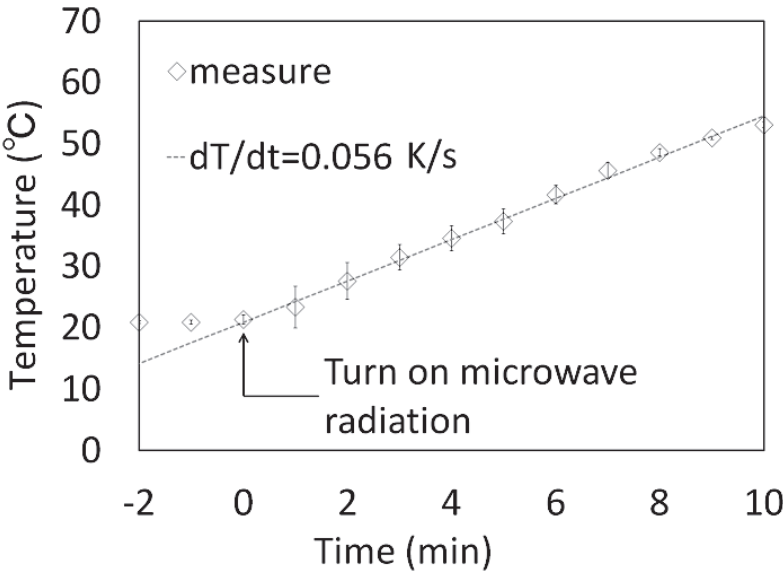

Fig. 11 Experimental temperature results and calculated heat loss. Gradient of the liner function is about $0.056 \mathrm{~K} / \mathrm{s}$ and the heat loss at $10 \mathrm{~min}$ was less than $3.5 \%$.

we measured the permittivity of woody biomas mixture. According to the measurement results, we confirmed the real part and imaginary part of permittivity decreased from 77.0 and 10.3 to 62.6 and 5.80 at temperature increase from $30^{\circ} \mathrm{C}$ to $90^{\circ} \mathrm{C}$, respectively. These measured values are used in the simulation model. In the 3D FEM simulation, the microwave irradiator was designed. According to the simulation results, we confirmed the less than $-30 \mathrm{~dB}$ reflection coefficient and 93\% absorption efficiency, respectively. We next fabricated a pilot-plant scale microwave irradiation reactor. In the experiment and discussion section, we showed the calculation method for absorption efficiency at reactor running. According to the experiment results, the $79 \%$ absorption efficiency was obtained. In this calculation, we confirmed $26.2 \%$ heat loss from $200^{\circ} \mathrm{C}$ metal pipe. Therefore, it is necessary for reducing the heat loss to use a insulating material in future.

Our study will contribute to the scaling up and practical use of woody biomass pretreatment reactors. In the future, we will enhance the microwave irradiating power and fabricate a plant-scale reactor for industrialization.

\section{Appendix: Calculation of Surface Temperature}

According to the Fourier's low in a cylindrical coordinate system, a heat flow $J$ from inside to outside of a pipe can be expressed by the following differential equation

$$
J=-2 \pi \kappa L_{\mathrm{p}} r \frac{\mathrm{d} T}{\mathrm{~d} r},
$$

where $\kappa$ is the heat-transfer coefficient of the pipe, $L_{\mathrm{p}}$ is the length of the pipe, and $r$ is the position in a radial direction. When we integrate from the inside radius $r_{\text {in }}$ to the outside radius $r_{\text {out }}$ of the pipe, Eq. (A-1) can be converted to following integral form

$$
\frac{J}{2 \pi \kappa L_{\mathrm{p}}} \int_{r=r_{\mathrm{in}}}^{r_{\mathrm{out}}} \frac{\mathrm{d} r}{r}=-\int_{T}^{T_{\mathrm{st}}} \mathrm{d} T .
$$

When we solve Eq. (A-2), $J$ can be written as 


$$
J=-\frac{\kappa S\left(T_{\text {st }}-T\right)}{r_{\text {out }} \ln \left(r_{\text {out }} / r_{\text {in }}\right)} .
$$

A thermal energy translated from the inner hot area is emitted to outside by radiation and convection at surface of the pipe. Therefore, the relationship of $J, Q_{\mathrm{r}}$, and $Q_{\mathrm{c}}$ is written as $J=Q_{\mathrm{r}}+Q_{\mathrm{c}}(=Q)$. Substitution of Eqs. (1), (2), and (A. 3 ) in this relationship and arrangement for $T_{\text {st }}$ lead to the following equation

$$
T_{\mathrm{st}}^{4}+A T_{\mathrm{st}}+B=0,
$$

where $A$ and $B$ are written as

$$
A=\frac{h}{e \sigma}+\frac{\kappa}{e \sigma r_{\text {out }} \ln \left(r_{\text {in }} / r_{\text {out }}\right)},
$$

and

$$
B=-T_{\mathrm{rt}}^{4}-\frac{h}{e \sigma} T_{\mathrm{rt}}-\frac{\kappa}{e \sigma r_{\mathrm{out}} \ln \left(r_{\mathrm{in}} / r_{\mathrm{out}}\right)} T .
$$

Solving Eq. (A.4) and determining a proper value from four solutions, we can get a value of surface temperature.

\section{Acknowledgment}

This work is supported by the New Energy and Industrial Technology Development Organization (NEDO) project, "Development of Technology for High-efficiency Conversion of Biomass and Other Energy." The estimate of the absorbed efficiency was discussed with Dr. Kasimura Keiichiro, Kyoto University.

\section{References}

[1] D. M. Gary, W. W. Wilbur, and E. M. Cliff, "Biomass pretreatment with water and high-pressure oxygen. The wet-oxidation process," Ind. Eng. Chem. Prod. Res. Dev., vol.22, no.2, pp.352-357, June 1983.

[2] T. Sawada, Y. Nakamura, F. Kobayashi, M. Kuwahara, and T. Watanabe, "Effects of fungal pretreatment and steam explosion pretreatment on enzymatic saccharification of plant biomass," Biotechnol. Bioeng., vol.48, no.6, pp.719-724, Dec. 1995.

[3] H. Itoh, M. Wada, Y. Honda, M. Kuwahara, and T. Watanabe, "Bioorganosolve pretreatments for simultaneous saccharification and fermentation of beech wood by ethanolysis and white rot fungi," J. Biotechnol., vol.15, no.103, Aug. 2003.

[4] T. Watanabe, "Trends in biorefinery and pretreatments of lignocellulosics by white rot fungi," J. Wood Sci., vol.53, no.1, pp.1-13, Sept. 2007.

[5] H. Ooshima, K. Aso, Y. Harano, and T. Yamamoto, "Microwave treatment of cellulosic materials for their enzymatic hydrolysis," Biotechnol. Lett., vol.6, no.5, pp.289-294, May 1984.

[6] J. Azuma, F. Tanaka, and T. Koshijima, "Microwave irradiation of lignocellulosic materials. I. Enzymatic susceptibility of microwaveirradiated woody plants," Mokuzai Gakkaishi, vol.30, no.6, pp.501509, June 1984.

[7] J. Azuma, J. Higashino, and M. Isaka, "Microwave irradiation of lignocellulosic materials. IV. Enhancement of enzymatic susceptibility of microwave-irradiated softwoods," Wood Res., no.71, pp.13-24, Feb. 1985.

[8] J. Azuma, J. Higashino, and T. Koshijima, "Microwave irradiation of lignocellulosic materials. VI. Enhancement of enzymatic susceptibility of softwood barks," Mokuzai Gakkaishi, vol.32, no.5, pp.351357, May 1986.
[9] J. Azuma, J. Higashino, and T. Koshijima, "Microwave irradiation of lignocellulosic materials. VIII. Microwave irradiation of the neutral fraction (C-I-M) of pine bjoerkman LCC," Wood Res., no.72, pp.111, Feb. 1986.

[10] K. Magara, S. Ueki, J. Azuma, and T. Kosijima, "Microwave irradiation of lignocellulosic materials. IX. Conversion of microwaveirradiated lignocellulose into ethanol," Mokuzai Gakkaishi, vol.34, no.5, pp.462-468, May 1988.

[11] K. Magara, J. Azuma, and T. Koshijima, "Microwave-irradiation of lignocellulosic materials X. Conversion of microwave-irradiated agricultural wastes into ethanol," Wood Res., no.76, pp.1-9, Dec. 1989.

[12] T. Mitani, M. Oyadomari, H. Suzuki, K. Yano, N. Shinohara, T. Tsumiya, H. Sego, and T. Watanabe, "A feasibility study on a continuous-flow-type microwave pretreatment system for bioethanol production from woody biomass," J. Jpn. st. Energy, vol.90, no.9, pp.881-885, Sept. 2011.

[13] J. Liu, R. Takada, S. Karita, T. Watanabe, and Y. Honda, "Microwave-assisted pretreatment of recalcitrant softwood in aqueous glycerol," Bioresource Tech., no.101, pp.9355-9360, Dec. 2010.

[14] K. Yano, T. Mitani, N. Shinohara, M. Oyadomari, M. Daidai, and T. Watanabe, "Microwave absorption characteristics of liquid compounds for an efficient microwave pretreatment system of woody biomass toward bioethanol production," Asia-Pacific Microwave Conference Proceedings (APMC), Yokohama, Japan, pp.53-56, 2010.

[15] T. Meissner and F. J. Wentz, "The complex dielectric constant of pure and sea water from microwave satellite observations," IEEE Trans. Geosci. Rem. Sens., vol.42, no.9, pp.1836-1849, Sept. 2004.

[16] T. Mitani, N. Shinohara, H. Matsumoto, and K. Hashimoto, "Improvement of spurious noises generated from magnetrons driven by DC power supply after turning off filament current," IEICE Trans. Electron., vol.E86-C, no.8, pp.1556-1563, Aug. 2003.

[17] T. Mitani, N. Shinohara, H. Matsumoto, M. Aiga, N. Kuwahara, and T. Ishii, "Noise-reduction effects of an oven magnetron with cathode shield on high-voltage input side," IEEE Trans. Electron. Dev., vol.53, no.8, pp.1929-1936, Aug. 2006.

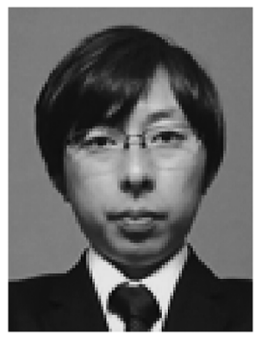

Naoki Hasegawa was born in Aichi, Japan, on June 18,1988 . He received his B.E. degree in electrical and electronic engineering from Ritsumeikan University, Siga, Japan, and his M.E. degree in electrical engineering from $\mathrm{Ky}$ oto University, Kyoto, Japan, in 2011 and 2013, respectively. $\mathrm{He}$ is a member of the Institute of Electronics, Information and Communication Engineers (IEICE), Japan. 


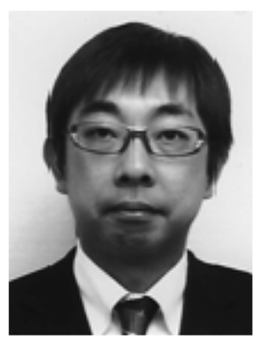

Mitani Tomohiko received his B.E. degree in electrical and electronic engineering, his M.E. degree in informatics, and his Ph.D. in electrical engineering from Kyoto University, Kyoto, Japan, in 1999, 2001, and 2006, respectively. He was an Assistant Professor with the Radio Science Center for Space and Atmosphere, Kyoto University, in 2003. He has been an Associate Professor with the Research Institute for Sustainable Humanosphere, Kyoto University, since 2012. His current research interests include experimental study on magnetrons, microwave power transmission systems, and applied microwave engineering.

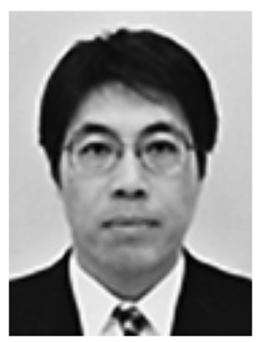

Naoki Shinohara received the B.E. degree in electronic engineering, the M.E. and $\mathrm{Ph} . \mathrm{D}$ (Eng.) degrees in electrical engineering from Kyoto University, Japan, in 1991, 1993 and 1996, respectively. He was a research associate in the Radio Atmospheric Science Center, Kyoto University from 1998. He was a research associate of the Radio Science Center for Space and Atmosphere, Kyoto University by recognizing the Radio Atmospheric Science Center from 2000 , and there he was an associate professor since 2001. He was an associate professor in Research Institute for Sustainable Humanosphere, Kyoto University by recognizing the Radio Science Center for Space and Atmosphere since 2004. From 2010, he has been a professor in Research Institute for Sustainable Humanosphere, Kyoto University. He has been engaged in research on Solar Power Station/Satellite and Microwave Power Transmission system. He is a member of the IEEE, URSI, the Institute of Electronics, Information and Communication Engineers (IEICE) and the Institute of Electrical Engineers of Japan (IEEJ)

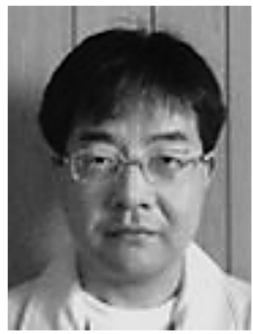

Masakazu Daidai received the B.E., M.E., and $\mathrm{Ph} . \mathrm{D}$. degree in chemical engineering from Kanazawa University, Ishikawa, Japan, in 2002, 2004, and 2008, respectively. In July 2008, he joined the Department of Environmental Resource, Prefectural University of Kumamoto, Japan, as a temporary assistant, and in April 2009, he joined the Research Institute for Sustainable Humanosphere, Kyoto University, as a researcher. Since 2012, he has been with Japan Chemical Engineering and Machinery Co., Ltd., Osaka, Japan, where he is currently the Senior Staff of R\&D department.

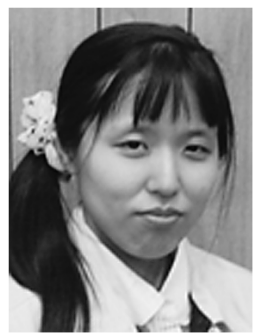

Yoko Katsura received the M.E. degree in Graduate school of engineering, from University of hyogo, Japan, in 2007, and have been working for a company called Japan Chemical Engineering and Machinery Co., Ltd., Osaka, Japan.
Hisayuki Sego

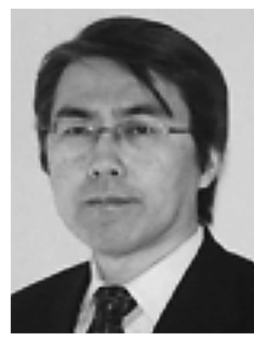

Takashi Watanabe was born in Nagoya in 1959. He is a Professor of Research Institute for Sustainable Humanosphere (RISH), Kyoto University. He received B.A. and M. A. degrees from Kyoto University in 1981 and 1983, respectively. He received a degree of D. A. from Kyoto University in 1989 . He was a visiting scientist of Institute of Biochemical Technology and Microbiology, University of Technology, Vienna in 1996-97. He is a Fellow of International Academy of Wood Science (IAWS). He was a Head of Center for Exploratory Research on Humanosphere, RISH, Kyoto University in 2008-10. He has been a Vice-Director of RISH since 2010. His major publications include, "Association of Lignin and Carbohydrates in Wood and Other Plant Tissues", (Springer-Verlag, Berlin, Germany, eds. by Koshijima, T. and Watanabe, T.). He is a leader of several national projects on production of biofuels and chemicals from lignocellulosics such as "Bioethanol Production from Woody Biomass using High efficient Microwave Reactions and Ethanologenic Bacteria," sponsored by NEDO. His major research interest is biological functions of lignin-degrading fungi and conversion of lignocellulosic biomass into biofuels and chemicals. 